\title{
Investigation of the Physiology and Architecture of Salmonella enteritidis Biofilms Under Alkaline Conditions
}

\author{
Aikaterina Papakonstantinou ${ }^{1}$ and Georgios Efthimiou ${ }^{2 *}$ \\ ${ }^{1}$ Strathclyde Institute of Pharmacy and Biomedical Sciences, University of \\ Strathclyde, 161 Cathedral Street,G4 ORE, Glasgow, United Kingdom \\ ${ }^{2}$ Department of Biomedical Sciences, University of Hull, Cottingham Road, HU6 7RX, \\ Hull, United Kingdom \\ *Corresponding Author: Georgios Efthimiou, Department of Biomedical \\ Sciences, University of Hull, Cottingham Road, HU6 7RX, Hull, United Kingdom. \\ E-mail: g.efthimiou@hull.ac.uk
}

DOI: 10.31080/ASMI.2020.03.0510
Received: January 27, 2020

Published: February 08, 2020

(C) All rights are reserved by Aikaterina

Papakonstantinou and Georgios Efthimiou.

\begin{abstract}
Formation of bacterial biofilms is an important survival strategy in multiple adverse environments. It is often affected by the nature of the attachment surface, the bacterial strain and the surrounding physicochemical conditions. The effect of low pH on biofilm formation has been well studied, in contrast to the alkaline range. The aim of this project was to study the effect of alkaline stress on the formation of biofilm by Salmonella enteritidis and to examine the biofilm architecture patterns under different conditions, by use of confocal microscopy. The optimal pH for Salmonella biofilm formation was found to be pH 7.0, while pH 10.0 (adjusted by use of sodium hydroxide) reduces it significantly ( $\mathrm{p}$-value $=0.015$ ). Planktonic cell growth was hindered due to the alkaline $\mathrm{pH}$, yet the number of viable cells remained high. In addition, the effect on biofilm formation was stronger when the alkaline stimulus was applied during stationary phase ( $9 \mathrm{~h}$ after inoculation). When the $\mathrm{pH}$ was adjusted to 10 by use of a commercial alkaline detergent (sodium carbonate or washing soda) similar results were observed. Finally, the biofilm architecture at pH 7.0 was characterized by small cell clusters, whereas at pH 10.0 a slightly thinner layer of individual cells was observed. These findings indicate that although most cells survive the alkaline stress, their ability to form biofilm is impaired at alkaline pH, potentially leading to new disinfectant strategies involving alkaline reagents.
\end{abstract}

Keywords: Salmonella enteritidis; Biofilm; Alkaline; Architecture; Detergents

\section{Introduction}

Salmonella enterica is a Gram- negative, rod-shaped facultative anaerobe pathogen of humans, which is responsible for causing serious food-borne infections around the world. Salmonella can be divided into more than 2600 serovars; Typhimurium and Enteritidis belong to the non-typhoidal Salmonella serovars [1] and are mostly known for causing gastroenteritis, a disease associated with intestinal inflammation and diarrhea, while it can also cause septicemia, osteomyelitis, pneumonia, meningitis, and arthritis [2]. In 2016, 94,530 cases of salmonellosis were reported in Eu- rope with Salmonella enteritidis being responsible for the majority of human cases to show an increase during 2016. It comes second after Campylobacter which is the most commonly reported gastrointestinal pathogenic bacterium and is a significant problem both in the food and the clinical settings [3]. Salmonella can affect humans through the consumption of contaminated food and water, while the cause of the infection in some cases is unknown [4]. The ability of Salmonella to produce biofilms on material commonly encountered in the food industry is considered the principal contamination reason of food-borne outbreaks [5]. 
Biofilms are extracellular polymeric structures (EPS) that surround bacterial populations giving them new properties. Their formation has been determined as one of the survival strategies of bacteria under environmental stress conditions, yet the underlying mechanism of biofilm formation has not been completely understood [6]. The bacteria become more resistant and insusceptible to external stimulation, such as antibiotics, extreme temperatures, $\mathrm{pH}$, exposure to anhydrous conditions or to the ultraviolet radiation, oxidative stress, and sanitizing agents, due to the architecturally complex shield that surrounds them [7]. Planktonic cells generate the formation of microcolonies along the attachment surface after their initial contact with surfaces and the formation of a monolayer. The expression of specific genes involved in the formation of the extracellular polysaccharide matrix is being activated [8]. Subsequently, when the attached bacteria have formed a three-dimensional polymer network, detachment mechanisms are being activated, since new surface colonization should begin leading to attachment and inoculation of other contact surfaces or even food $[9,10]$.

Several studies have been conducted studying the impact of the surrounding environment, such as $\mathrm{pH}$, temperature, nutrient availability, to the biofilm production and have concluded the several parameters and the complexity affecting this phenomenon, as well as the significance of sanitizing agents for the public health More specifically, the duration of the bacterial exposure to acid stress, the $\mathrm{pH}$ value and the origin of the acid have been found to influence the biofilm production $[12,13]$. It has been observed that the antimicrobial effect ranges among organic acids and it depends on the concentration, the $\mathrm{pH}$ and the structure [14]. Gallic acid and ferrulic acid (phenolic acids) were found to reduce the biofilm activity in four pathogenic bacteria; Escherichia coli (E. coli), Pseudomonas aeruriginosa (P. aeruriginosa), Staphylococcus aureus (S. aureus) and Listeria monocytogenes (L. motocytogenes). The organic acids seem to alter the physicochemical characteristics of the cells which influence the adhesion potential and the inhibition of the bacterial mobility [15]. Furthermore, experiments in the Gram-negative E. coli demonstrated the inhibitory effect of gallic acid on genes related to biofilm production, as it was recently published [16]. Malic acid managed to inhibit S. typhimurium biofilm formation in carrot and other food product surfaces, while its combined treatment with ozone leads to the reduction of biofilm formation on plastic material [17].
In addition, the attachment surface as well as the conditions under which a biofilm is being formed are related to the sensitivity of the biofilm to sanitizers [18]. Biofilms formed by S. typhimurium have shown resistance to chlorination and the efficiency of the treatment is dependent on the attachment surface [19]. Preformed $P$. aeruriginosa biofilms were shown to be more elastic after their treatment with citric acid [20]. Moreover, experiments in E. coli, S. enteritidis and $S$. aureus have shown that different chlorine treatments exert different impact on the inactivation of the biofilm, while widely used acidic ( $\mathrm{pH}$ 6.40), neutral ( $\mathrm{pH}$ 6.72), and alkaline detergents ( $\mathrm{pH}$ 7.76) did not inactivate the formed biofilms [21]. Meanwhile, in a similar study performed on S. aureus and S. epidermidis bacterial cells, alkaline $\mathrm{pH}$ exerted a significant impact on the inhibition of biofilm formation and on the adherence to the attachment surface [22].

The effect of the alkaline conditions in the biofilm production and resistance to antimicrobials has not been studied widely, even though alkaline solutions seem to possess antimicrobial properties to Salmonella biofilms [23]. Salmonella biofilms act as contamination vessels, affecting the factory hygiene and product safety and thus causing microbial diseases. The risks associated with the presence of Salmonella biofilms in food-related surfaces and clinical settings highlight the importance of finding new disinfectants and understanding the spatial differences of biofilms. As a result, having an insight into the physiology of the biofilms and factors associated with bacterial survival strategy may open a new field in the effective prevention and mitigation of the human pathogens.

Biofilm communities possess different functions based on their three-dimensional organization of the bacterial cells. Biofilms have diffusion, reaction delays which are responsible for their antimicrobial properties, and are related to the matrix shape and the biofilm architecture [24,25]. As the biofilm develops, the structural, chemical and physiological heterogeneity leads to different gene expression and more specifically cell activity [26]. As a result, techniques aiming to provide structural data of the biofilms have been developed and used in this field; such as confocal laser scanning microscopy (CLSM), preferred when biofilms need to be investigated on the single cell $[27,28]$. CLSM is widespread in the recent literature, due to the ability of isolating and collecting a plane of focus within a sample, as well as the selection of optical sections from thick specimens $[29,30]$. 
Hence, the objective of this study was to determine the effect of $\mathrm{pH}$ (7 and 10) and time ( $24 \mathrm{~h}, 48 \mathrm{~h}, 72 \mathrm{~h}$, and $96 \mathrm{~h}$ ) on the biofilm formation by $S$. enteritidis as well as the viability of biofilm cells treated with alkaline $\mathrm{pH}$. Additionally, the biofilm architecture was studied under neutral and alkaline conditions in order to observe the changes of the cell morphology and have an insight to genetic changes triggered by the environmental $\mathrm{pH}$.

\section{Materials and Methods}

\section{Strain and growth conditions}

The non-pathogenic strain S. enterica serovar Enteritidis (NCTC4444) was cultured during the experiments in order to analyse its phenotype regarding both its biofilm-forming and planktonic behaviour. Single colonies of $S$. enteritidis were cultured on Tryptone soy broth (TSB) (Merck, Germany) at $37^{\circ} \mathrm{C}$. The cultures were diluted 20 times in the desired media using 24-well polystyrene microtiter plates (TPP ${ }^{\circledR}$ Europe, Switzerland). The $\mathrm{pH}$ of the media was adjusted with sodium hydroxide $(\mathrm{NaOH})$ in order to achieve values in the $\mathrm{pH}$ range $4-11$ and the $\mathrm{pH}$ measurements were performed using a pH meter (Corning pHmeter 140).

Sodium carbonate $\left(\mathrm{Na}_{2} \mathrm{CO}_{3}\right.$ washing soda) (Sigma Chemical Co.) was used as a pH buffer of TSB medium, while Elma ${ }^{\mathrm{TM}} 70$ (Thermo Fisher Scientific) was also used in different concentrations, as an antibacterial detergent (Table 1). Elma ${ }^{\mathrm{TM}} 70$ is composed by 5 $15 \% \mathrm{w} / \mathrm{w}$ Na-alkyl-PEG-ether ester of phosphoric acid, $<5 \mathrm{w} / \mathrm{w} \%$ disodium metasilicate, $5-15 \% \mathrm{w} / \mathrm{w}$ tetrapotassium pyrophosphate, and $5 \mathrm{w} / \mathrm{w} \%$ cocosfatty acid amidopropyldimethylaminoxide. The plates were incubated at $37^{\circ} \mathrm{C}$ for different time intervals. The concentration of the resulting bacterial suspension was estimated through optical density measurements $\left(\mathrm{OD}_{600 \mathrm{~mm}} ; 10 \mathrm{~mm}\right.$ cuvette pathlength; Eppendorf BioPhotometer), as well as the final $\mathrm{pH}$ of the cultures was assessed using universal $\mathrm{pH}$-indicator roll (Tritest pH 1-11, Macherey-Nagel, Germany). The surface-attached cells were stained and the microtiter plate biofilm assay was performed in every experiment.

\section{Biofilm quantification: Crystal violet assay (CV assay)}

The biofilm formed after each experiment was estimated using the crystal violet absorption method. The planktonic bacteria were removed and three washing steps using $1 \mathrm{~mL}$ of sterile water were made in every well. Then, the remaining cells were stained using $1 \mathrm{~mL}$ of CV (1\% v/v; Pro-lab Diagnostics), allowing the visualisa-

\begin{tabular}{|c|c|c|c|}
\hline \multicolumn{4}{|l|}{ TSB } \\
\hline $\begin{array}{l}\text { Concentration of so- } \\
\text { dium carbonate added } \\
(\% \mathrm{w} / \mathrm{v})\end{array}$ & pH & $\begin{array}{c}\text { Concentration of } \\
\text { Elma }^{\mathrm{TM}} 70 \text { added } \\
(\% \mathrm{v} / \mathrm{v})\end{array}$ & pH \\
\hline 1 & 10.18 & 20 & 10.68 \\
\hline 0.5 & 9.64 & 10 & 9.7 \\
\hline 0.25 & 8.38 & 8 & 9.31 \\
\hline \multirow[t]{5}{*}{0.1} & 8.18 & 5 & 8.96 \\
\hline & & 2 & 7.88 \\
\hline & & 1 & 7.56 \\
\hline & & 0.5 & 7.23 \\
\hline & & 0.1 & 7.01 \\
\hline
\end{tabular}

Table 1: Additional media used in this study.

tion of the biofilm. After $10 \mathrm{~min}$, the excess $\mathrm{CV}$ was removed with several washes and the stained biofilms were then solubilised in 1 $\mathrm{mL}$ of $70 \% \mathrm{v} / \mathrm{v}$ ethanol and $30 \% \mathrm{v} / \mathrm{v}$ acetone per well. The absorbance of each well was measured at $550 \mathrm{~nm}$ using the Ultrospec ${ }^{\mathrm{TM}}$ 3100pro UV/Visible spectrophotometer (Amersham Biosciences).

\section{Viability assay}

The number of attached cells was monitored at $24 \mathrm{~h}$ in TSB pH 7.0 and $\mathrm{pH}$ 10.0. Briefly, the 24-well plate was carefully washed three times with $1 \mathrm{~mL}$ of sterile water. The wells were swabbed to detach the biofilm cells and several dilutions were performed $\left(10^{-1}\right.$ $\left.10^{-6}\right)$. One hundred microliters of the diluted cell suspensions with appropriate dilutions were plated on solid Nutrient agar. Plates were incubated at $37^{\circ} \mathrm{C}$ and after $24 \mathrm{~h}$, colony-forming units (CFU, well $^{-1}$ ) and the number of viable bacteria were calculated.

\section{Microscopy experiments}

S. enteritidis was cultured on cover glass $(22 \times 22$, square, 0.13 - $0.17 \mathrm{~mm}$, Ultident Scientific) in TSB pH 7.0 (control group) and pH 10.0 (stress group) during $24 \mathrm{~h}$. Each biofilm sample was then stained, using $200 \mu \mathrm{L}$ of a fluorescent stain of bacterial viability (6:1000 dilution from a Syto9 stock solution at $1.67 \mathrm{mM}$ and a 3.2:1000 dilution from a Propidium iodide stock solution at 18.7 $\mathrm{mM}$ in filter-sterilized water), and was incubated for $30 \mathrm{~min}$ at room temperature protected from the light. A confocal laser scanning microscope was used for the observation of the live and dead cells, as well as the biofilm architecture. 


\section{Confocal laser scanning microscope (CLSM)}

Leica SP5 Confocal laser scanning microscope (LEICA Microsystems, France) was used in order to obtain images of the biofilms. All biofilms were scanned using an oil-immersion lens with $20 \mathrm{x}$ magnitude and an argon laser set at 30\% intensity. Emitted fluorescence was recorded within the range $492-512 \mathrm{~nm}$ in order to visualise Syto9 fluorescence and within $600-675 \mathrm{~nm}$ in order to visualise PI fluorescence. Three stacks of horizontal (x direction) and vertical ( $\mathrm{y}$ direction) plane images $(1024 \times 1024$ pixels corresponding to $192.92 \times 193.2 \mu \mathrm{m}$ ) with a section thickness of 3.087 $\mu \mathrm{m}$ were taken for each biofilm, as well as zoomed pictures ( $\mathrm{x} 4)$. Z-volume was also quantified through z-stack and z-step size was set as $3.11 \mu \mathrm{m}$. Both section thickness and step size were determined by the calibration of the microscope, and mainly by the numerical aperture of the objective and the diameter of the confocal pinhole. The equipment was operated using LAS-AF Software and image construction was performed through ImageJ (free available software).

\section{Statistical analysis}

Paired t-test was performed using Mini Tab 17 (Pennsylvania State University, USA). The bacteria in both stress and control groups resulted from the same strain and the absorbance and OD at $550 \mathrm{~nm}$ and $600 \mathrm{~nm}$, respectively, were normally distributed.

\section{Results}

Effect of media, incubation time and $\mathrm{pH}$ on S. enteritidis biofilms S. enteritidis was tested for the production of biofilms on polystyrene 24-well plates in media of different $\mathrm{pH}$ values.

The results of long-term exposure ( 24 h-96 h) of Salmonella under extreme $\mathrm{pH}$ conditions are depicted in figure 1 . Significant differences were observed in both biofilm formation and the planktonic phase when comparing the acidic and alkaline range with the control ( $\mathrm{pH}$ 7.0). More specifically, regarding the acidic range, the biofilm production was increased with increasing $\mathrm{pH}(\mathrm{pH} 4.0$ to 6.0), whereas significant differences were observed for $\mathrm{pH} 8.0, \mathrm{pH}$ 9.0 $(\mathrm{p}$-value $=0.007)$ and $\mathrm{pH} 10.0(p$-value $=0.015)($ Figure $1 \mathrm{~A})$. Additionally, the growth in the planktonic phase differs depending on the $\mathrm{pH}$; $\mathrm{pH} 9.0$ does not seem to hinder the multiplication of the bacteria, while $\mathrm{pH} 4.0-6.0,10.0$, and 11.0 suppress their growth (Figure1B).
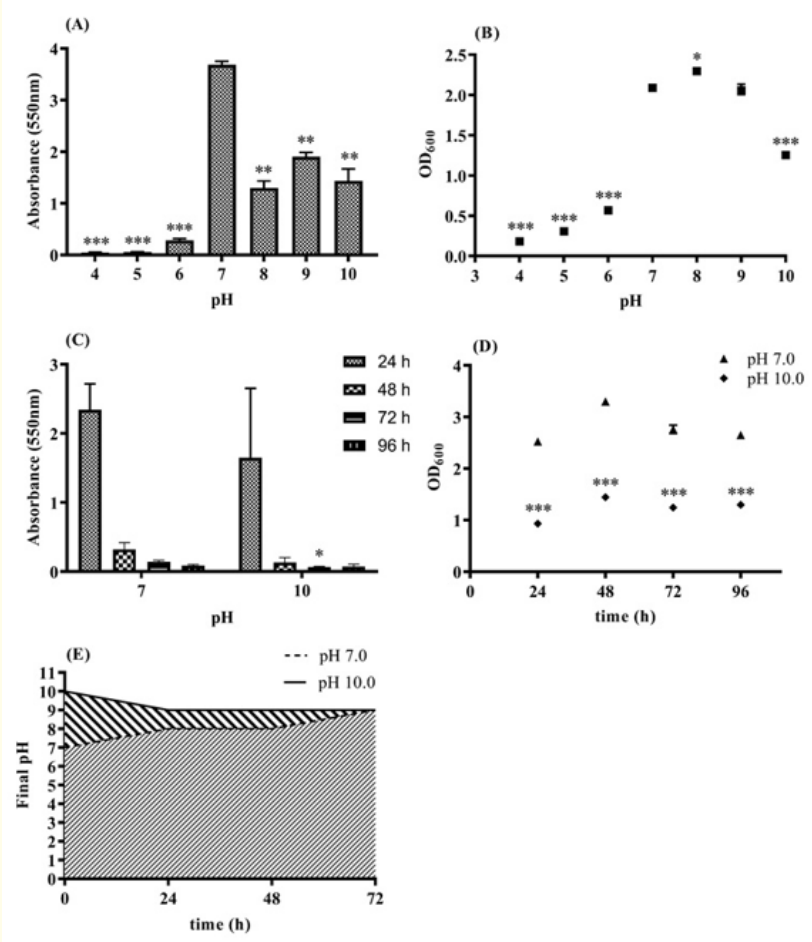

Figure 1: Biofilm formation (A) and planktonic cell growth (B) at a range of $\mathrm{pH}$ (4-10) after $24 \mathrm{~h}$ in TSB (Tryptone soy broth). Biofilm formation (C) and planktonic cell growth (D) over time ( $24 \mathrm{~h}, 48$ h, 72 h, 96 h) in TSB. Final pH was measured every 24 $\mathrm{h}$ when the initial pH was 7.0 and 10.0 (E). The statistical differences resulted from comparison with the control ( $\mathrm{pH}$ 7.0) for the three replicates that were tested $(\mathrm{N}=3)$ in each case. $\mathrm{p}$-values are indicated in the graphs when statistical differences are present, comparing to the control $\mathrm{pH} 7.0$ ( $\mathrm{p} \leq 0.05$; * is used when $\mathrm{p} \leq 0.05$, $* *$ when $\mathrm{p} \leq 0.01$, and ${ }^{* * *}$ when $\mathrm{p} \leq 0.001$ ). The biofilm formation was estimated semi-quantitatively through absorbance measurements at $550 \mathrm{~nm}$, whereas the concentration of bacterial cells was estimated through optical density (OD) measurements at $600 \mathrm{~nm}$.

In the time-course (Figure $1 \mathrm{C}$ ), at $24 \mathrm{~h}$ the biofilm formation was high, both in pH 10.0 and pH 7.0 (Average $A_{550}=1.650$ in pH 10.0 and Average $A_{550}=2.344$ in $\mathrm{pH} 7.0$ ). Significant differences were present only at $72 \mathrm{~h}$ when comparing $\mathrm{pH} 10.0$ with the control ( $p$-value $=0.016$ ); yet, the measured absorbance was low (Average $\left.A_{550}=0.075\right)$. It is worth to mention that in the case of $\mathrm{pH} 10.0$ and 
pH 7.0, the wells had totally different configuration of biofilm; in $\mathrm{pH}$ 10.0, more biofilm was formed at the bottom of the well, although in $\mathrm{pH}$ 7.0, the biofilm was mostly concentrated in the walls of the well. Differences were also observed in the planktonic growth due to the impact of the alkaline $\mathrm{pH}(p$-value $=0.001)$ (Figure 1D).

Moreover, the final $\mathrm{pH}$ was measured at four time points for two initial pHs in the different media; pH 7.0 and pH 10.0 (Figure 1E). It was observed that the bacterial cultures regardless the initial $\mathrm{pH}$ reach $\mathrm{pH}$ 9.0; in $\mathrm{pH} 10.0$ the transition to $\mathrm{pH} 9.0$ is made during the first $24 \mathrm{~h}$ and then is stable, whereas in $\mathrm{pH} 7.0$ there is a gradual increase during the $96 \mathrm{~h}$ in order to reach the final $\mathrm{pH}$. The $\mathrm{pH}$ remained stable after $96 \mathrm{~h}$.

Furthermore, the addition of sodium hydroxide in different time intervals ( $0 \mathrm{~h}, 3 \mathrm{~h}, 6 \mathrm{~h}$, and $9 \mathrm{~h}$ ) in TSB pH 7.0 aimed to change the $\mathrm{pH}$ to $\mathrm{pH} 10.0$, and the measurements were made after $24 \mathrm{~h}$. Sodium hydroxide affected the biofilm formation only when added at $9 \mathrm{~h}$ ( $p$-value $=0.018$ ) (Figure $2 \mathrm{~A})$ showing that the alkaline $\mathrm{pH}$ is determining in the biofilm formation after $9 \mathrm{~h}$. The planktonic cells got reduced with the addition of sodium hydroxide (Figure 2B).
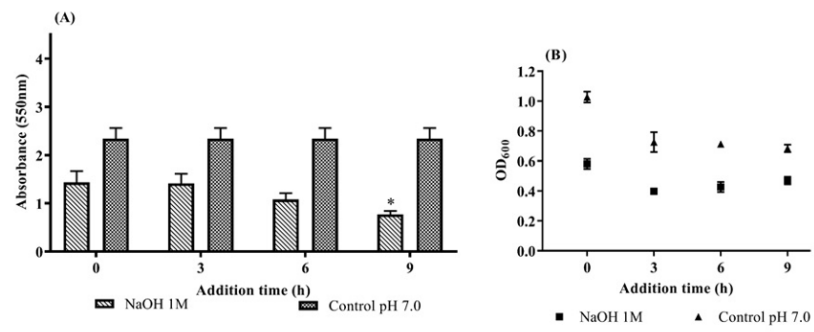

Figure 2: Biofilm formation (A) and planktonic cell growth (B) after the addition of sodium hydroxide $(\mathrm{NaOH})$ in specified time points ( $0 \mathrm{~h}, 3 \mathrm{~h}, 6 \mathrm{~h}$, and $9 \mathrm{~h}$ ) at $24 \mathrm{~h}$. Set volumes of sodium hydroxide were added in TSB (Tryptone soy broth) (pH 7.0), reaching $\mathrm{pH}$ 10.0. The statistical differences resulted from comparison with the control ( $\mathrm{pH} 7.0$ ) in each case, for the three replicates that were tested $(\mathrm{N}=3)$. $\mathrm{p}$-values are indicated in the graphs when statistical differences are present, comparing to the control pH 7.0 ( $\mathrm{p} \leq 0.05$; ${ }^{*}$ is used when $\mathrm{p} \leq 0.05$, ** when $\mathrm{p} \leq 0.01$, and ${ }^{* * *}$ when $\mathrm{p} \leq 0.001$ ). The biofilm formation was estimated semi-quantitatively through absorbance measurements at 550 $\mathrm{nm}$, whereas the concentration of bacterial cells was estimated through optical density (OD) measurements at $600 \mathrm{~nm}$.
Different TSB solutions were prepared using sodium carbonate as a buffer; $0.1 \%$ and $0.25 \%$ led to $\mathrm{pH}$ of 8.18 and 8.38 , respectively, while higher concentrations corresponding to a $\mathrm{pH}$ range of 9.64 - 10.18 led to cell death. The concentrations of sodium carbonate that mimicked $\mathrm{pH} 8.0$ led to altered amount of biofilm when compared to the control ( $\mathrm{pH} 7.0$ ) ( $p$-value $=0.017$ when $0.1 \%$ and $p$-value $=0.046$ when $0.25 \%$ ) (Figure $3 \mathrm{~A}$ ). Moreover, the $0.25 \%$ solution seems to have influenced the growth of the planktonic cells $(p$-value $=0.004)($ Figure 3B) .
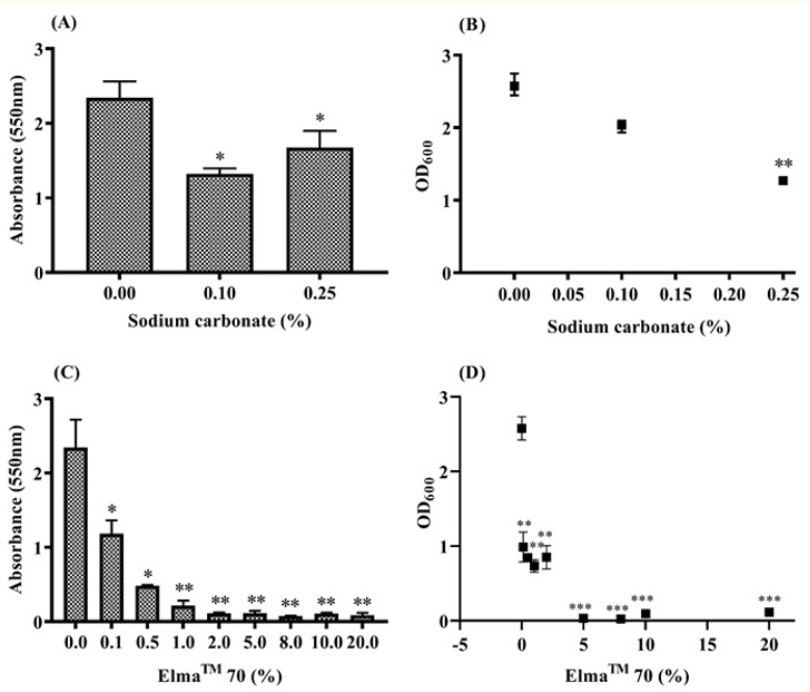

Figure 3: Biofilm formation and planktonic cell growth after the adjustment of the $\mathrm{pH}$ using sodium carbonate $(\mathrm{A})(\mathrm{B})$ and $\mathrm{Elma}^{\mathrm{TM}}$ 70 (C)(D), respectively, after $24 \mathrm{~h}$. Sodium carbonate was used as an alkaline $\mathrm{pH}$ buffer in $0-0.25 \%$ in TSB media. Elma ${ }^{\mathrm{TM}} 70$ was used as an alkaline detergent in different concentrations (0-20\%).

The statistical differences resulted from comparison with the solution $0 \%$ in each case, for the three replicates that were tested $(\mathrm{N}=3)$. p-values are indicated in the graphs when statistical differences are present, comparing to the control pH 7.0 ( $\mathrm{p} \leq 0.05$; * is used when $\mathrm{p} \leq 0.05{ }^{* *}$ when $\mathrm{p} \leq 0.01$, and ${ }^{* * *}$ when $\mathrm{p} \leq 0.001$ ). The biofilm formation was estimated semi-quantitatively through absorbance measurements at $550 \mathrm{~nm}$, whereas the concentration of bacterial cells was estimated through optical density (OD) measurements at $600 \mathrm{~nm}$. 
Similarly, different concentrations of the detergent Elma ${ }^{\mathrm{TM}} 70$ led to significant differences when compared to the control $(\mathrm{pH}$ 7.0) (0.1\%, pH 7.01; 0.5\%, pH 7.23; 1\%, pH 7.56, 2\%, pH 7.88; 5\%, pH 8.96, 8\%, pH 9.31, 10\%, pH 9.7; 20\%, pH 10.68) (Figure 3C, 3D). Biofilm formation was hindered by the detergent leading to even more significant differences with the increase of its concentration in TSB. It is noted that even when the $\mathrm{pH}$ of the processed media was 7.01, significant difference was present in comparison with the control $(\mathrm{pH} 7.0)(p$-value=0.033)

\section{Cell viability}

The amount of live cells was estimated by calculation of CFU, based on the amount of colonies created in the tested conditions (Table 2). The pH tested were pH 7.0 and 10.0; in TSB, significant differences were observed between the amount of live cells present ( $p$-value $=0.001$ ). This difference was also quantified using the average CFU in each case; for $\mathrm{pH} 10.0$, the amount of live cells was 24 times less than in $\mathrm{pH}$ 7.0.

\begin{tabular}{|l|c|c|}
\hline TSB & pH 7.0 & pH 10.0 \\
\hline \multirow{3}{*}{ CFU $\left(\right.$ well $\left.^{-1}\right)$} & $7.1 \mathrm{E}+08$ & $5.7 \mathrm{E}+07$ \\
\cline { 2 - 3 } & $8.0 \mathrm{E}+08$ & $2.6 \mathrm{E}+07$ \\
\cline { 2 - 3 } & $9.2 \mathrm{E}+08$ & $2.7 \mathrm{E}+07$ \\
\cline { 2 - 3 } & $6.7 \mathrm{E}+08$ & $1.9 \mathrm{E}+07$ \\
\hline \multirow{2}{*}{ Average CFU (well $\left.{ }^{-1}\right)$} & $7.8 \mathrm{E}+08$ & $3.2 \mathrm{E}+07$ \\
\hline Standard Deviation & $1.1 \mathrm{E}+08$ & $1.7 \mathrm{E}+07$ \\
\hline p-value & \multicolumn{2}{|c|}{$0.001(* * *)$} \\
\hline
\end{tabular}

Table 2: Colony forming units (CFU, well-1) of biofilm bacteria formed in neutral and alkaline $\mathrm{pH}$ in TSB. Basic statistical analysis of the four replicates $(\mathrm{N}=4)$ was performed and the presence of statistical differences regarding the viability of biofilm cells was evaluated comparing to the control group ( $\mathrm{pH} 7.0)$.

\section{Microscopy analysis}

Biofilm structures formed after $24 \mathrm{~h}$ were observed using CLSM for TSB medium in pH 7.0 and pH 10.0 (Figure 4). A remarkable difference was found in the cell configuration between the two biofilms; in $\mathrm{pH} 7.0$, S. enteritidis tends to form scattered cell clusters, while in $\mathrm{pH} 10.0$ only individual cells were observed in the biofilm. Free-of-cells areas were also identified. The majority of the biofilm-associated cells were alive, and no obvious differences were observed in the cell viability between the two conditions, even though no cell quantification was performed. On the other hand, z-stacks performed in the CLSM allowed the quantification of the $\mathrm{z}$-volume, providing the thickness of the formed biofilm (Table 3). Step size is defined as the distance in $\mu \mathrm{m}$ between each captured image received in the z-axis, and results from the section thickness. The number of steps is chosen through manual imaging, using top and bottom focal planes and the total distance between those two is the sample thickness. A slight difference between the thickness of the biofilm at $\mathrm{pH} 7.0$ and $\mathrm{pH} 10.0$ was observed ( $\mathrm{p}$-value $=$ 0.205). The biofilms formed at $\mathrm{pH} 7.0$ were slightly thicker than those formed at $\mathrm{pH} 10.0$ (z-volume $=24.898 \mu \mathrm{m}$ in $\mathrm{pH} 7.0$ and average $\mathrm{z}$-volume $=20.229 \mu \mathrm{m}$ in $\mathrm{pH} 10.0$ ).
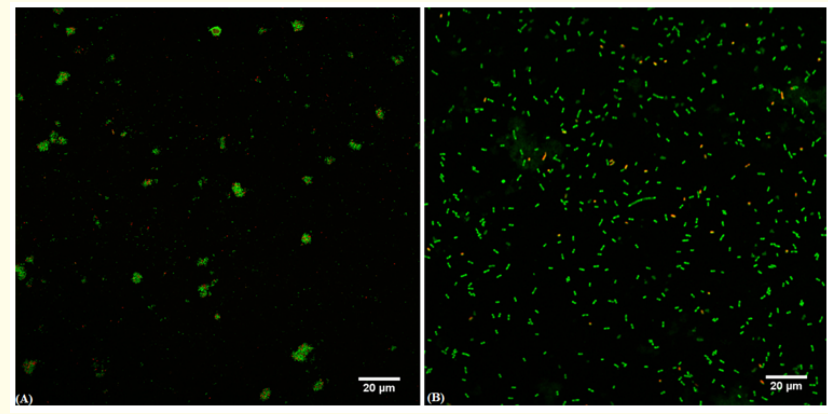

Figure 4: Confocal laser scanning microscopy images $\mathrm{S}$. enteritidis biofilms formed under $\mathrm{pH} 7.0$ (A) and $\mathrm{pH} 10.0$ (B) conditions. A lens of x20 magnitude was used to provide a field-of-view feature. The viable cells are labeled with Syto9 (green fluorescent dye) and the dead ones with PI (red fluorescent dye). Two replicates were prepared for the study of the biofilm architecture.

\begin{tabular}{|c|c|c|c|}
\hline \multicolumn{2}{|c|}{ pH 7.0 } & \multicolumn{2}{c|}{ pH 10.0 } \\
\hline $\begin{array}{c}\text { Number of } \\
\text { steps }\end{array}$ & $\begin{array}{c}\text { z-volume } \\
(\boldsymbol{\mu m})\end{array}$ & $\begin{array}{c}\text { Number of } \\
\text { steps }\end{array}$ & $\begin{array}{c}\text { z-volume } \\
(\boldsymbol{\mu m})\end{array}$ \\
\hline 9 & 24.898 & 8 & 21.785 \\
\hline 9 & 24.898 & 7 & 18.673 \\
\hline
\end{tabular}

Table 3: Thickness of the biofilm formed under neutral and alkaline conditions. The section thickness and z-step size were set as 3.085 $\mu \mathrm{m}$ and $3.11 \mu \mathrm{m}$, respectively. The number of necessary steps in the $\mathrm{z}$-axis was determined by the thickness of the biofilm. 


\section{Discussion}

The effects of incubation time and $\mathrm{pH}$ were investigated regarding the development of $S$. enteritidis biofilm, as well as the resistance to detergents used both domestically and in a laboratory or industrial setting. Especially, alkaline range of $\mathrm{pH}$ was of main interest, since the majority of previous studies and antimicrobial agents are focused on the effect of the acids in biofilms. The ability of $S$. enteritidis to grow over a range of $\mathrm{pH}$ conditions and media was confirmed by this study ( $\mathrm{pH} 4.0$ - 11.0), although the tolerance of this strain to environmental stress ( $\mathrm{pH} 5.3$ - 9.0) is already known when lactic acid and trisodium phosphate were used to acidify and alkalize the media (TSB-incubation: 18h) [31]. Considering the results obtained, $\mathrm{pH} 10.0$ was selected as standard for the alkaline range for the medium tested (TSB) (Figure 1C, 1D, 1E).

S. enteritidis can develop biofilms in all of the different time intervals that were investigated providing significantly different results in $72 \mathrm{~h}$ when compared with the control. However, $24 \mathrm{~h}$ was selected as the incubation time for TSB cultured samples, because biofilm quantity in the other time points was too low to allow comparisons of biofilm formation among different $\mathrm{pH}$ conditions (Figure 1C). Similarly, in previous studies Salmonella cultures were incubated in TSB at $37^{\circ} \mathrm{C}$ for $18 \mathrm{~h}$ and $24 \mathrm{~h}[10,32]$.

Significant differences were also present in the alkaline range, apart from those present in the acidic range (Figure 1A, 1B). It has been reported that the biofilm-forming ability was decreased in the presence of acid for S. typhimurium, whereas S. Infantis strain (bdar morphotype) and most S. enterica strains produce more biofilm at lower pH [33,34]. Similarly with effects observed even in strong-biofilm forming Salmonella serotypes (S. enterica Newport) [10], the amount of biofilm was increasing in higher $\mathrm{pH}$ conditions in this study, and optimum $\mathrm{pH}$ for biofilm formation on polystyrene well plate is $\mathrm{pH}$ 7.0. A similar phenomenon was observed at pH 5.0 and 7.0 when stainless steel was the attachment surface $[33,35]$. These results support the hypothesis that biofilm formation activity is strain-dependent and more importantly, dependent on the morphotype. Regarding the alkaline range, not many reports are available in the literature except when extracellular matrix proteins were used as an attachment surface. In contrast to our finding, no significant differences were found for media at $\mathrm{pH}$ range 5.0 - 9.0 [12]. Regarding the planktonic growth of $S$. enteritidis between the different $\mathrm{pH}$ conditions tested, it was observed that under alkaline conditions, where biofilm was formed, growth of single cells was higher (Figure 4B). However, the use of mathematical models has revealed that bacterial growth is not a prerequisite for biofilm formation, due to the fact that these two variables are two discrete functions of bacterial life [10]. Further research should be performed in order to investigate the environments that both free and attached cells are exposed to in detail.

Remarkably, the growth and formation of bacterial biofilm was different between $\mathrm{pH} 10.0$ and $\mathrm{pH}$ 7.0. The biofilm amount at $\mathrm{pH}$ 7.0, was higher in the air-liquid surface, leading to higher attachment in the walls of the wells, whereas at $\mathrm{pH} 10.0$, the bottom surface of the wells was the main attachment area. It seems that $\mathrm{pH}$ 10.0 influences the swarming motility of the bacteria, reducing its ability to move along the surfaces to spread [36]. Biofilm development at the air-liquid interface facilitates gas exchange, as well as nutrient and water acquisition from the media. As a result, biofilms produced in air-liquid interfaces are a threat to industrial water systems [33]. However, $\mathrm{pH} 10.0$ seems to trigger the aggregation of the bacteria at the bottom of the containers, leading to new areas for investigation in order to end the problems with biofilms formed in the air-liquid at $\mathrm{pH}$ 7.0.

Even though carbonate ions form insoluble ligands with divalent metal ions, vital for the proper function of enzymes and membranes of Salmonella [37], in contrast to previous work, neither planktonic cell growth nor biofilm formation was inhibited (Figure 3 ). The range of values obtained was similar to those when the $\mathrm{pH}$ of the media was altered, showing that the observed effects came from the $\mathrm{pH}$ of the media and not from dying owing to metal chelation. TSB at pH 8.18 and 8.38 ( $0.1 \%$ and $0.25 \%$ Sodium carbonate) had significant differences in biofilm formation and in planktonic cells, showing once more that alkaline $\mathrm{pH}$ exerts an impact in the formation of the biofilm.

Elma $^{\text {TM }} 70$ is used as an alkaline detergent in laboratory setting. It is distributed commercially in a concentrated solution and used at $1 \%$ to $5 \%$ and 5 to $10 \%$ in a bath with and without ultrasounds, respectively. When used as advised, the biofilm formation is efficiently decreased. Yet, when diluted 10-times more than the suggested lower limit, reaching $\mathrm{pH} 7.01$, development of biofilm was visible (Figure $3 \mathrm{~A}$ ). This finding suggests that the elimination of the biofilm was not due to the $\mathrm{pH}$, but owing to the ingredients that are present on it, which affect the bacterial growth. The anionic and

Citation: Aikaterina Papakonstantinou and Georgios Efthimiou. "Investigation of the Physiology and Architecture of Salmonella enteritidis Biofilms Under Alkaline Conditions". Acta Scientific Microbiology 3.3 (2020): 01-11. 
amphoteric surfactants included have antimicrobial properties [38], as well as the sodium metasilicate present is able of disrupting the cytoplasmic membrane, due to its high pH (11-12) [39].

The number of viable cells in $\mathrm{pH} 7.0$ was estimated 24-times higher than that observed for $\mathrm{pH} 10.0$ (Table 2). Thus, the cell viability of the biofilm seems to be affected by nutrient availability and environmental conditions as Castelijn G. A. A., et al. reported before [40]. However, the microscopy results did not indicate remarkable differences in the cell viability. The different cell organization observed between $\mathrm{pH} 7.0$ and 10.0 in TSB indicates that alkaline $\mathrm{pH}$ leads to different gene expression patterns and affects significantly the biofilm architecture (Figure 4A, 4B). Individual cells were present in the stress group (pH 10.0) (Figure 4B), whereas cell aggregates were formed in control group ( $\mathrm{pH} 7.0)$ (Figure 4A). Likewise, small scattered cells were reported again for $S$. enteritidis in $\mathrm{pH} 7$ [25]. EPS connects the individual cells during biofilm formation, organizing them in aggregates that are the main responsibles of resistance against environmental stress and endurance to different surfaces. More specifically, curli fimbriae mediate the cell-cell aggregation and together with cellulose, polysaccharides and proteins form connections between the wide range of multi-cells. S. typhimurium experiments performed in microcolonies revealed physiological differences between aggregated and non-aggregated cells; the aggregated cells had enhanced resistance to disinfectants and as a result higher survival rate in non-host environment compared to the non-aggregated group [41]. Thus, it can be assumed that the amount of EPS was reduced by the alkaline stress, similarly with the reduction that acid stress had on the size of cell clusters in stainless steel [35]. The bacterial biofilm formed under alkaline conditions could be connected to lower resistance to antimicrobials and as a result, easier eradication of the biofilm. Further experiments using Attenuated Total Reflection Fourier Transform Infra-Red (ATR-FTIR) of functional groups of EPS or fluorescently labeled lectins [42] could provide evidence on this EPS-lacking hypothesis during alkaline growth conditions. More data regarding the biofilm patterning field and the antimicrobial properties are needed, in order to assess how alkaline conditions affect biofilms when being formed, as well as potential novel features. The elucidation of the mechanism leading to this bacterial behavior could indicate a way of tackling biofilm development. Cellulose, one of the main constituents of the biofilm, can also be measured through calcofluor staining, allowing correlation between biofilm resistance and $\mathrm{pH}$ [7].
The microscopy methods performed were also combined with staining methods of viable and non-viable bacteria, offering a wider overview of how $\mathrm{pH}$ affects the biofilm structure. The methods used in order to measure the bacterial viability were CFU counting of cultured plates and live-dead staining. Both techniques showed different results for alkaline $\mathrm{pH}$ in cell viability within the biofilm, on a first glance; the CFU method showed that $\mathrm{pH} 10.0$ reduces cell viability by 24 times in comparison with that of $\mathrm{pH} 7.0$, yet the microscopy pictures obtained did not indicate obvious differences. Regarding the CFU method, it is suspected that either the high degree of aggregation due to the biofilm matrix led to mistaken conclusion, or the swabbing of the biofilm in order to perform the plating caused dissolution of the formed clusters in $\mathrm{pH}$ 7.0. Yet, neither CLSM led to the calculation of viable and non-viable cells. Due to the fact that there was no quantitative estimation of the viable cells through live/dead staining and CLSM, the effectiveness of the $\mathrm{pH}$ environment regarding the cell viability cannot be assessed yet. One possible goal for this project would be the quantification of bacterial viability through metabolic assays [43].

The average depth of the biofilms formed in $\mathrm{pH} 7.0$ and $\mathrm{pH} 10.0$ was also measured, illustrating changes in the biofilm thickness (Table 3), possibly resulting from the size of the cell aggregates formed in $\mathrm{pH} 7.0$ [44]. Yet, the observed differences in our study do not appear significant ( $p$-value $=0.205$ ). Biofilm thickness is also associated with diffusion limitation and thus, substrate penetration in the biofilm [45]. Further experiments in order to assess the permeability of thinner biofilms ( $\mathrm{pH} 10.0)$ in antibacterial reagents need to be performed. Then, CLSM combined with IMARIS 7.0 Software (Bitplane, Switzerland) could be used in order to quantify further structural parameters of the biofilm samples, including biovolume, substratum coverage and roughness [25]. The resulting three-dimensional projections of the structures would enable the study of virulence and antimicrobial biofilm traits in different conditions [46].

It has to be noted that the microscopy experiments were performed in a glass surface, while the rest of the experiments in a polystyrene microtiter plate. Polystyrene is hydrophobic [47], in contrast to glass which is hydrophilic and bacteria, as Salmonella, adhere more to hydrophobic surfaces [48]. Differences in plate surface and microscopy experiments, as far as it is known, affects only the numbers of bacteria present. However, the surface is an important factor for bacteria adhesion and a direct comparison between 
the two types of biofilm produced can not be done based on our data. Future work should focus on the study of Salmonella behavior in stainless steel surface, widely used in food industry [49].

In conclusion, alkaline $\mathrm{pH}$ exerts a great impact on biofilm formation of $S$. enteritidis changing the cell motility, aggregation structure and biofilm architecture. The survival of Salmonella was reduced due to the alkaline environment, however the number of viable cells remained significantly high. The changes in $\mathrm{pH}$ are not sufficient in order to eradicate the biofilm development and additional detergent compounds need to be used. The effect of the alkaline $\mathrm{pH}$ in the biofilm formation seems to be important even in late time intervals after inoculation, giving the opportunity for new cleaning protocols involving alkaline detergents. New innovative strategies need to be found to control issues regarding microbes in food-processing environments, aiming to reduce the food spoilage, and the associated economic losses, as well as to improve the global food safety, jeopardized by disease transmission caused by biofilms.

\section{Conflicts of Interest}

The authors declare that there are no conflicts of interest.

\section{Funding Information}

This work was supported by Strathclyde Institute of Pharmacy and Biomedical Sciences.

\section{Acknowledgements}

We are grateful to Liam Rooney and Graeme MacKenzie for their contribution and guidance during the microscopy experiments. We would also like to thank Thomas Hender for his technical assistance.

\section{Bibliography}

1. Gal-Mor 0., et al. "Same species, different diseases: how and why typhoidal and non-typhoidal Salmonella enterica serovars differ". Frontiers in Microbiology 5 (2014): 1-10.

2. Trevejo RT., et al. "Epidemiology of Salmonellosis in California, 1990 - 1999: Morbidity, Mortality, and Hospitalization Costs". American Journal of Epidemiology 157 (2003): 48-57.

3. EFSA and ECDC. "The European Union summary report on trends and sources of zoonoses, zoonotic agents and foodborne outbreaks in 2016". EFSA Journal 15 (2017): 1-227.
4. MacKenzie KD., et al. "Bistable Expression of CsgD in Salmonella enterica Serovar Typhimurium Connects Virulence to Persistence". Infection and Immunity 83 (2015): 2312-2326.

5. Wang H., et al. "In situ characterization and analysis of Salmonella biofilm formation under meat processing environments using a combined microscopic and spectroscopic approach". International Journal of Food Microbiology 167 (2013): 293302.

6. Hall-Stoodley L., et al. "Bacterial biofilms: From the natural environment to infectious diseases". Nature Reviews Microbiology 2 (2004): 95-108.

7. Yang Y., et al. "Biofilm formation of Salmonella Enteritidis under food-related environmental stress conditions and its subsequent resitance to chlorine treatment". Food Microbiology 54 (2016): 98-105.

8. Davies DG and Geesey GG. "Regulation of the alginate biosynthesis gene algC in Pseudomonas aeruginosa during biofilm development in continuous culture". Applied and Environmental Microbiology 61 (1995): 860-867.

9. Costerton JW., et al. "Bacterial Biofilms: A Common Cause of Persistent Infections”. Science 284 (1999):1318-1322.

10. Dimakopoulou-Papazoglou D., et al. "Modelling biofilm formation of Salmonella enterica ser. Newport as a function of $\mathrm{pH}$ and water activity". Food Microbiology 53 (2016): 76-81.

11. Annous BA., et al. "Quorum Sensing in Biofilms: Why Bacteria Behave the Way They Do". Journal of Food Science 74 (2009): R24-R37.

12. Zulfakar SS., et al. "Effect of $\mathrm{pH}$, salt and chemical rinses on bacterial attachment to extracellular matrix proteins". Food Microbiology 34 (2013): 369-375.

13. Cirkovic I., et al. "Influence of organic and inorganic acids on biofilm formation by Salmonella spp". International Journal of Antimicrobial Agents 29 (2007): 610-611.

14. Chaveerach P., et al. "In vitro study on the effect of organic acids on Campylobacter jejuni/coli populations in mixtures of water and feed". Poultry Science 81 (2002): 621-628.

15. Borges A., et al. "The activity of ferulic and gallic acids in biofilm prevention and control of pathogenic bacteria". Biofouling 28 (2012): 755-767. 
16. Kang J., et al. "The specific effect of gallic acid on Escherichia coli biofilm formation by regulating pgaABCD genes expression". Applied Microbiology and Biotechnology 102 (2018): 1837-1846.

17. Singla R., et al. "Novel synergistic approach to exploit the bactericidal efficacy of commercial disinfectants on the biofilms of Salmonella enterica serovar Typhimurium". Journal of Bioscience and Bioengineering 118 (2014): 34-40.

18. Joseph B., et al. "Biofilm formation by Salmonella spp. on food contact surfaces and their sensitivity to sanitizers". International Journal of Food Microbiology 64 (2001): 367-372.

19. Scher K., et al. "Effect of Heat, Acidification, and Chlorination on Salmonella enterica Serovar Typhimurium Cells in a Biofilm Formed at the Air-Liquid Interface". Applied and Environmental Microbiology 71 (2005): 1163-1168.

20. Lieleg O., et al. "Mechanical robustness of Pseudomonas aeruginosa biofilms". Soft Matter 7 (2011): 3307-3314.

21. Ueda S and Kuwabara Y. "Susceptibility of Biofilm Escherichia coli, Salmonella Enteritidis and Staphylococcus aureus to Detergents and Sanitizers". Biocontrol Science 12 (2007): 149153.

22. Nostro A., et al. "Effect of alkaline pH on staphylococcal biofilm formation". Acta Pathologica et Microbiologica Scandinavica 120 (2012): 733-742.

23. Speranza B., et al. "Approaches to Removal and Killing of Salmonella Spp. Biofilms". Journal of Food Processing and Preservation 41 (2017): 1-9.

24. Lewis K. "Riddle of Biofilm Resistance". Antimicrob Agents Chemother 45 (2001): 999-1007.

25. Bridier A., et al. "The biofilm architecture of sixty opportunistic pathogens deciphered using a high throughput CLSM method". Journal of Microbiological Methods 82 (2010): 64-70.

26. Stewart PS. "Diffusion in Biofilms". Journal of Bacteriology 185 (2003): 1485-1491.

27. Caricate-Nero A and Bergantin LB. "Importance of fluorescence microscopy in the study of the dysfunctions of intracellular Ca2+ homeostasis invovled in pathogenesis of cardiovascular diseases". Nuclear Medicine and Molecular Imaging 2 (2017): 1-7.
28. Plank M., et al. "Millisecond timescale slimfield imaging and automated quantification of single fluorescent protein molecules for use in probing complex biological processes". Integrative Biology 1 (2009): 602-612.

29. Dige I., et al. "In situ identification of streptococci and other bacteria in initial dental biofilm by confocal laser scanning microscopy and fluorescence in situ hybridization". European Journal of Oral Sciences 115 (2007): 459-467.

30. Quintas V., et al. "Analyzing the oral biofilm using fluorescencebased microscopy: what's in a dye? Microscopy: Advances in scientific research and education". Formatex Research Center, Editors: A. Méndez-Vilas (2014): 226-238.

31. Yang Y., et al. "Membrane lipid composition and stress/virulence related gene expression of Salmonella Enteritidis cells adapted to lactic acid and trisodium phosphate and their resistance to lethal heat and acid stress". International Journal of Food Microbiology 191 (2014): 24-31.

32. Speranza B., et al. "Effects of nutritional and environmental conditions on Salmonella sp. biofilm formation". Journal of Food Science 76 (2011): 12-16.

33. Karaca B., et al. "Biofilm-producing abilities of Salmonella strains isolated from Turkey". Biologia 68 (2013): 1-10.

34. Lianou A and Koutsoumanis KP. "Strain variability of the biofilm-forming ability of Salmonella enterica under various environmental conditions". International Journal of Food Microbiology 160 (2012): 171-178.

35. Wang H., et al. "Response of long-term acid stress to biofilm formation of meat-related Salmonella Enteritidis". Food Control 69 (2016): 214-220.

36. Singh R., et al. "Biofilms: implications in bioremediation". Trends in Microbiology 14 (2006): 389-397.

37. Jarvis GN., et al. "The mechanism of carbonate killing of Escherichia coli”. Letters in Applied Microbiology 33 (2001): 196-200.

38. Zhang L., et al. "Lighting up the interactions between bacteria and surfactants with aggregation-induced emission characteristics". Materials Chemistry Frontiers 1 (2017): 1829-1835.

39. Sapers GM. "Disinfection of contaminated produce with conventional washing and sanitizing technology". Chapter in: The Produce Contamination Problem. Second Edition. Academic Press, Elsevier, The Netherlands (2009). 
40. Castelijn GA., et al. "Diversity in biofilm formation and production of curli fimbriae and cellulose of Salmonella Typhimurium strains of different origin in high and low nutrient medium". Biofouling 28 (2012): 51-63.

41. White AP., et al. "Aggregation via the red, dry, and rough morphotype is not a virulence adaptation in Salmonella enterica serovar typhimurium". Infection and Immunity 76 (2008):1048-1058.

42. Neu T., et al. "Assessment of lectin- binding analysis for in situ detection of glycoconjugates in biofilm systems". Microbiology 147 (2001): 299-313.

43. Pantanella F., et al. "BioTimer Assay, a new method for counting Staphylococcus spp. in biofilm without sample manipulation applied to evaluate antibiotic susceptibility of biofilm". Journal of Microbiological Methods 75 (2008): 478-484.

44. Murga R., et al. "Quantitative analysis of biofilm thickness variability". Biotechnology and Bioengineering 45 (1995): 503-510.

45. Torresi E., et al. "Biofilm thickness influences biodiversity in nitrifying MBBRs - Implications on micropollutant removal". Environmental Science and Technology 50 (2016): 9279-9288.

46. Hu M., et al. "Determination of porosity and thickness of biofilm attached on irregular-shaped media". Journal of Environmental Engineering 139 (2013): 923-931.

47. Ryu J and Beuchat LR. "Biofilm formation by Escherichia coli 0157: H7 on stainless steel: Effect of exopolysaccharide and curli production on its resistance to chlorine". Applied and Environmental Microbiology 71 (2005): 247-254.

48. Díez-García M., et al. "Influence of serotype on the growth kinetics and the ability to form biofilms of Salmonella isolates from poultry". Food Microbiology 31 (2012): 173-180.

49. Van Houdt R and Michiels CW. "Biofilm formation and the food industry, a focus on the bacterial outer surface". Journal of Applied Microbiology 109 (2010): 1117-1131.

\section{Assets from publication with us}

- Prompt Acknowledgement after receiving the article

- Thorough Double blinded peer review

- Rapid Publication

- Issue of Publication Certificate

- High visibility of your Published work

Website: https://www.actascientific.com/

Submit Article: https://www.actascientific.com/submission.php

Email us: editor@actascientific.com

Contact us: +919182824667 